\title{
Simplified frozen elephant trunk repair for acute DeBakey type I dissection
}

Eric E. Roselli, MD, Aldo Rafael, MD, Edward G. Soltesz, MD, Leonardo Canale, MD, and Bruce W. Lytle, MD

Objective: The study objective was to describe a novel technique and assess the safety and feasibility of this initial experience for performing a modified frozen elephant trunk extended repair of acute dissection.

Methods: From June 2009 to February 2012, 17 patients with DeBakey type I acute aortic dissections underwent emergency surgery using a new approach for extended repair of the ascending arch and proximal descending aorta with a hybrid technique. Fourteen patients were male $(82 \%)$ with a mean age of $61.4 \pm 17.5$ years. Some 8 of $17(47 \%)$ presented with malperfusion, and the mean time from symptom onset to operating room was $12.8 \pm 3.7$ hours. Two patients had root replacement with a stentless bioprosthesis, 1 patient had aortic valve replacement, 13 patients had the valve resuspended, and 1 patient had the native valve reimplanted as a David procedure. A single, commercially available descending thoracic stent graft (26-37 mm TAG, WL Gore and Associates, Flagstaff, Ariz) was delivered antegrade directly into the open descending aorta, trimmed proximally, and sutured into the arch of each patient. The left subclavian artery was covered in 8 of 17 patients $(47 \%)$. Data were from a prospectively collected database. Follow-up computed tomography was performed at discharge, 3 months, and annually, and assessed with 3-dimensional reconstruction.

Results: There were no perioperative deaths, and all patients are still alive at intermediate follow-up. There were 2 strokes without residual deficit, and 2 patients had paraparesis postoperatively with recovery before discharge. Two patients required temporary tracheostomy for respiratory failure, and 3 patients required temporary hemodialysis. The mean length of stay was $20 \pm 12$ days, 10 of which were in the intensive care unit. At imaging follow-up, the proximal aortic repair was stable in all patients, and the false lumen was thrombosed in the treated segment in $87.5 \%$ of patients.

Conclusions: A novel simplified frozen elephant trunk hybrid technique for acute type I dissections allows for safe and effective extended aortic repair with false lumen thrombosis and aortic remodeling of the treated segment. Long-term outcomes of this technique warrant further investigation. ( $\mathrm{J}$ Thorac Cardiovasc Surg 2013;145:S197-201)

Video clip is available online.

Proximal aortic dissection requires emergency surgical repair to prevent mortality related to instability of the most proximal aorta. ${ }^{1}$ The majority of survivors have extensive involvement of the aorta (DeBakey type I), leaving them at risk for late complications from degeneration of the more distal aorta. ${ }^{2,3}$ It has been demonstrated that the patency of the distal false

\footnotetext{
From the Department of Thoracic and Cardiovascular Surgery, Heart and Vascular Institute, Cleveland Clinic, Cleveland, Ohio.

Disclosures: Drs Roselli, Rafael, Soltesz, Canale, and Lytle have nothing to disclose with regard to commercial support.

Read at The American Association for Thoracic Surgery Aortic Symposium, New York, New York, April 26-27, 2012.

Received for publication May 14, 2012; revisions received Aug 2, 2012; accepted for publication Nov 28, 2012; available ahead of print Dec 20, 2012.

Address for reprints: Eric E. Roselli, MD, Cleveland Clinic, 9500 Euclid Ave, Desk J4-1, Cleveland, OH 44195-5108 (E-mail: roselle@ ccf.org).

$0022-5223 / \$ 36.00$

Copyright (C) 2013 by The American Association for Thoracic Surgery

http://dx.doi.org/10.1016/j.jtcvs.2012.11.068
}

lumen after acute proximal repair increases the risk for later reoperation and reduces late survival. ${ }^{4}$

As stent grafts have become widely available for the treatment of thoracic aortic disease, their use in combination with conventional open approaches, or hybrid techniques, has expanded. ${ }^{5,6}$ One hybrid aortic repair method, commonly referred to as the "frozen elephant trunk procedure," has been applied to patients with extensive aortic dissection in multiple reports. ${ }^{7-14}$ The experience with frozen elephant trunk repair in acute dissection has demonstrated reasonable results, but the operation has not gained wide favor because of limited access to specially designed devices and the perceived complexity of the procedure.

A novel simplified frozen elephant trunk repair technique for acute proximal dissection has been developed at the Cleveland Clinic. The objectives of this study are to describe the operation and assess safety and efficacy.

\section{PATIENTS AND METHODS}

Between June 2009 and February 2012, 17 patients presenting with DeBakey type I acute aortic dissection underwent emergency surgical repair 


\section{Abbreviation and Acronym \\ $\mathrm{CT}=$ computed tomography}

with a novel frozen elephant trunk technique for extended repair of the ascending aorta, arch, and upper descending aorta during the same surgical intervention. The population included 14 men $(82 \%)$ : Age varied from 29 to 87 years (mean, $61.4 \pm 17.5$ years). The clinical presentation of the aortic dissection was chest/back pain in 9 patients $(53 \%)$, isolated distal malperfusion in 1 patient $(6 \%)$, and both phenomena in 7 patients $(41 \%)$. The median time between the onset of pain and the arrival at the operating room was 12.8 hours (range, 3-254 hours). Fifteen patients (88\%) underwent surgery within 41 hours of the development of symptoms, and 2 patients initially presented with distal aortic dissections that progressed to proximal dissections after failing initial medical therapy. On the basis of intraoperative description, the location of the main entry tear was the ascending aorta only in 9 patients, the arch only in 4 patients, the descending aorta only in 1 patient, and multiple locations in 3 patients. Patient characteristics are shown in Table 1.

\section{Operative Technique}

All operations were performed in a hybrid operating room under general anesthesia. Preferred arterial cannulation was via a side graft on the right axillary artery, but 2 patients required central aortic cannulation using a modified Seldinger technique with echocardiographically guided wire placement because of hemodynamic instability from tamponade. Patients were cooled to $18^{\circ} \mathrm{C}$ before circulatory arrest. During the cooling phase, percutaneous access was obtained into the ascending aorta with a $100-\mathrm{cm}$ angled Glide catheter over a Glidewire (Terumo, Ann Arbor, Mich). Once the patient achieved an adequate level of cooling, the circulation was arrested. The aorta was opened and transected at the level of the innominate artery in a standard hemiarch fashion. Through-and-through wire access was obtained by delivering a 260-cm Amplatz wire (Cook Medical, Bloomington, Ind) into the pre-positioned catheter through the open aorta. This allowed for easy and safe antegrade delivery of the stent graft into the open aorta. The stent graft was then deployed with the proximal end of the device at the proximal edge of the opened aortic arch. By using a rightangled wire cutter, 2 of the flares on the stent graft were resected to create a "fenestration" around the supra-aortic branch vessel (left subclavian or left common carotid artery). The stent graft at the base of this fenestration was then sutured to the base of the branch artery with a pledgeted mattress suture of 4-0 Prolene. Two to four additional pledgeted mattress "tacking" sutures were placed within the aortic arch to fix the stent graft within the mid to distal aortic arch. The distal aortic hemi-arch anastomosis was then performed in the usual fashion for acute aortic dissection, with a beveled Dacron graft reinforced with felt or bovine pericardial strips. This anastomosis was performed in the usual way except for the additional detail that the stent graft was included within the anastomosis as a "neointimal" layer around 220 degrees of the circumference (Figure 1). The proximal portion of the operation was performed as usual, depending on the status of the patient's aortic root. Additional operative details are shown in Table 1.

\section{Device Selection and Positioning}

GORE TAG stent grafts (Gore Medical, Flagstaff, Ariz) were used in all patients, and the most common size was $34 \mathrm{~mm}$ (range, 26-37 mm). Three patients received $10-\mathrm{cm}$ devices, and the rest $(82 \%)$ were $15 \mathrm{~cm}$. Sizing of the device was based on the overall aortic diameter at the level of the midarch between the left carotid and left subclavian arteries, based on 3-dimensional multiplanar reconstructions. The device was delivered to a level so that the most proximal portion of the stent graft was positioned at the lesser curve edge of the arch. This led to coverage of the left subclavian artery in 8 patients ( $47 \%$ ). Four patients received additional stents to branch vessels. One was placed directly into the left subclavian artery through the open aorta because of excessive narrowing at the origin from suturing of the stent graft. This patient had a patent left internal thoracic artery to the left anterior descending artery. The other 3 patients had distal organ ischemia requiring stenting of 1 superior mesenteric artery and 2 iliac arteries. A fifth patient initially presented with a distal dissection treated medically, but then progressed to renal failure and more proximal involvement; he had an additional stent graft placed distal to the frozen elephant trunk because of persistent true lumen collapse distal to the primary repair.

\section{Follow-up}

Follow-up was performed as a regularly scheduled outpatient visit with blood pressure monitoring and imaging with computed tomography (CT). CT images of the chest, abdomen, and pelvis with arterial and delayed venous phase contrast were acquired before discharge, at 3 months, and annually. Images were analyzed using 3-dimensional reconstruction software (TeraRecon, San Mateo, Calif) to assess for stability of the repair, device integrity, endoleaks, and false lumen thrombosis (Figure 2). Imaging follow-up was complete in 16 patients (94\%) at a mean of $154 \pm 144$ days.

Standard descriptive statistical analyses were used. Continuous variables are presented as the mean \pm standard deviation or median with range (because of the small sample size), and categoric variables are presented as percentages.

\section{RESULTS}

Surgery was successfully completed with accurate device delivery in all patients. Early and intermediate outcomes are presented in Table 2. There were no hospital deaths. Two patients who had a stroke have no residual deficits. Two patients with leg weakness postoperatively recovered completely with optimal medical therapy. One patient was dialysis-dependent preoperatively. The 3 patients requiring new postoperative hemodialysis have recovered renal function and are no longer dialysis- dependent. The 2 patients who underwent tracheostomy have been weaned from the ventilator successfully.

Three patients had type 2 endoleak from the left subclavian artery. One patient required embolization and additional distal aortic stent grafting because of documented aortic growth 6 months postoperatively. His upper descending aorta was more than $4 \mathrm{~cm}$ in diameter at initial presentation. False lumen thrombosis of the treated segment of the descending aorta was observed in 14 of the 16 patients $(87.5 \%)$ at late follow-up. One patient did not have a follow-up CT scan because of billing issues.

The status of the dissected aorta beyond the stent grafted segment is variable. Four patients $(25 \%)$ have no residual dissection, and 12 patients $(75 \%)$ have residual distal dissection to varying extents: 3 are confined to the distal thoracic aorta, 1 extends to the mesenteric segment, 1 extends to the infrarenal aorta, 6 extend to the iliac arteries, and 1 extends to the femoral arteries.

\section{DISCUSSION}

The primary goal of surgery for acute proximal aortic dissection is to save the patient from dying of rupture, 
TABLE 1. Patient characteristics and operative details

\begin{tabular}{lc}
\hline Single anastomosis frozen elephant trunk repair & $\mathbf{n}=\mathbf{1 7}(\%)$ \\
\hline Patient characteristics & \\
Mean age (y \pm SD; range, 29-87) & $61.4 \pm 17.5$ \\
Presentation & \\
$\quad$ Back/chest pain & $9(53)$ \\
Ischemia & $8(47)$ \\
Both & $7(41)$ \\
Median interval symptoms to OR (h, range) & $12.8(3-254)$ \\
Location of entry tear & \\
Ascending only & $9(53)$ \\
Arch only & $4(24)$ \\
Proximal descending only & $1(6)$ \\
Multiple proximal locations & $3(18)$ \\
Operative details & \\
Mean circulatory arrest (min \pm SD) & $28 \pm 4$ \\
Left subclavian artery covered & $8(47)$ \\
Aortic valve management & $13(76)$ \\
Resuspension & $2(12)$ \\
Biologic root replacement & $1(6)$ \\
Valve-sparing aortic root reimplantation & $1(6)$ \\
Bioprosthetic aortic valve replacement & $5(30)$ \\
Additional concurrent vascular stenting &
\end{tabular}

$S D$, Standard deviation; $O R$, operating room.

tamponade, or malperfusion. ${ }^{1}$ As the results have improved at centers of excellence, there has been a growing interest in achieving the secondary goal of distal aortic remodeling for patients presenting with extensive dissection (DeBakey type 1). The safety and feasibility of the novel simplified technique for performing extended repair are demonstrated by the experience described.

This method not only promotes false lumen thrombosis within the segment of aorta that is most vulnerable to late aneurysmal degeneration but also may be successful at addressing acute distal ischemia. Excellent results were achieved in the patients who presented with end-organ ischemia, approximately half the patients in the series. By bringing all patients who present with DeBakey type 1 dissection to the hybrid operating room for treatment, the opportunity for saving lives is optimized because of ready access to the most modern tools and techniques.

This is not the first report demonstrating the feasibility of extended repair for extensive aortic dissection, or even the first report describing the use of antegrade stent graft delivery for achieving this goal. ${ }^{7-15}$ However, the method described maintains the simplicity of the 2-anastomosis hemiarch repair technique used during conventional repair with an interposition graft. The circulatory arrest time was consistently less than 30 minutes, and the operation has been applicable to a diverse mix of patients.

In a recently published extensive review of the elephant trunk procedure and its variations, the mean mortality was $6 \%$ for the frozen elephant trunk procedure, $5 \%$ for stroke, and $6 \%$ in spinal cord injury in a population of 700 patients

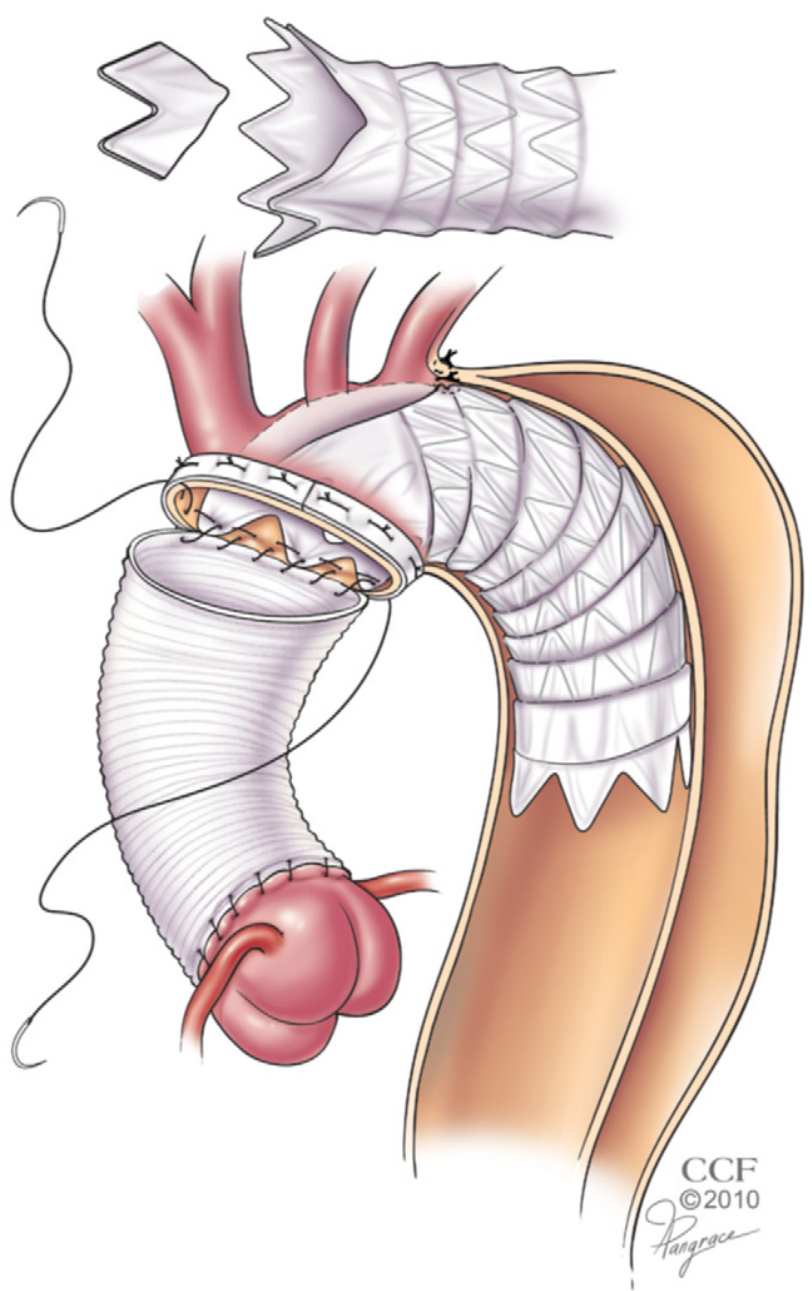

FIGURE 1. The simplified frozen elephant trunk repair technique with direct suturing of the stent graft to the surgical ascending graft within the aortic arch. Note the modification to the stent graft by removal of 2 of the flares to create an opening under the supra-aortic branches.

including 400 dissections. ${ }^{16}$ In the current experience, morbidity and mortality were at least comparable to these prior reports and could be considered low given the high percentage of patients presenting with ischemia, a known risk for hospital mortality. ${ }^{17}$

In the current version of this procedure, the stent graft device is commercially available, but used outside the instructions for use. Because the GORE TAG stent graft is composed of 3 separate nitinol frames ( 1 for the main body and 2 supporting each of the flared ends), the trimming of a couple of the flares does not disrupt the integrity of the device. Although a $10-\mathrm{cm}$ device was used during a couple of the earlier procedures, it did not provide adequate length to lie entirely around the curve of the arch. A $15-\mathrm{cm}$ device was used to treat the rest of the patients to address that issue, but none of the $20-\mathrm{cm}$ devices were used because of risk of spinal cord injury. It has been shown in previous 


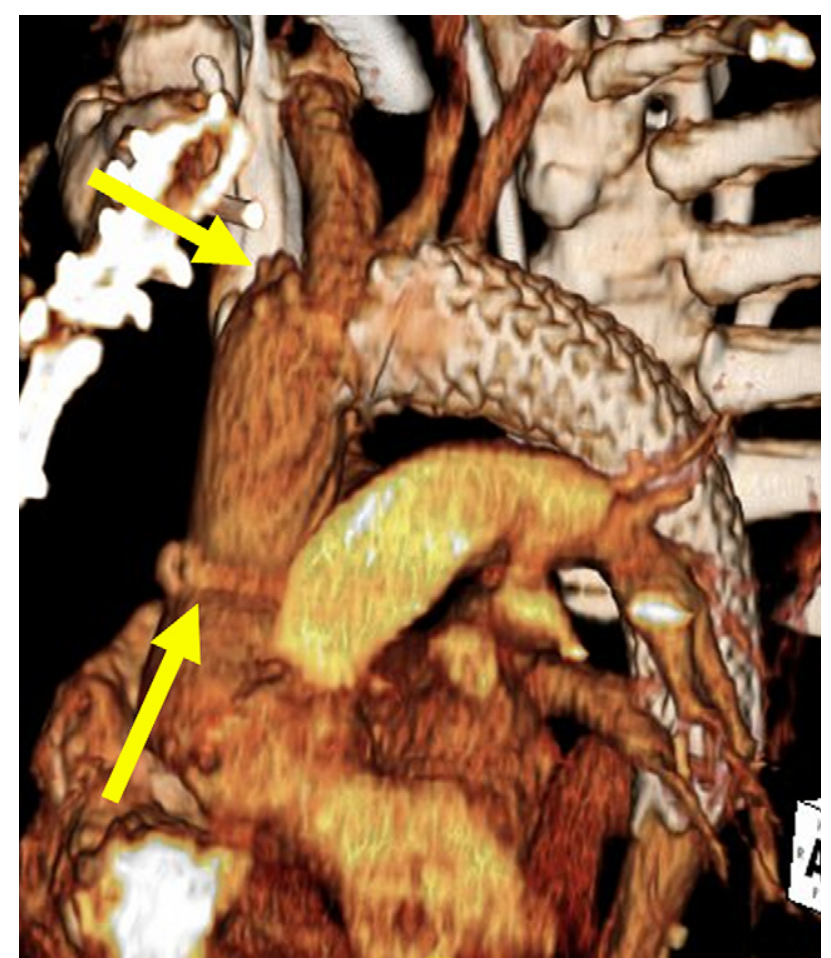

FIGURE 2. Volume-rendered 3-dimensional reconstruction of the postoperative CT scan. Arrows point to the proximal and distal aortic suture lines.

experiences that more extensive coverage of the aorta during endovascular or hybrid procedures is associated with a risk of spinal cord injury. ${ }^{18,19}$

Some have argued that performance of any more than the simplest proximal repair in the setting of acute dissection is unnecessary because the more distal aorta can be addressed during a second elective operation. Although it is true that both open and endovascular choices are available for the treatment of chronic dissections, the results of these operations are less than ideal. ${ }^{20-22}$ The chances for getting the false lumen of the aorta to heal are best during the acute phase of injury. The segment of distal aorta that is most

\begin{tabular}{lc} 
TABLE 2. Outcomes & \\
\hline Single anastomosis frozen elephant trunk repair & $\mathbf{n}=\mathbf{1 7}(\%)$ \\
\hline Acute outcomes & \\
Hospital mortality & $0(0)$ \\
Stroke & $2(12)$ \\
Paraplegia & $0(0)$ \\
Temporary paraparesis & $2(12)$ \\
Tracheostomy & $2(12)$ \\
New hemodialysis & $3 / 16(19)$ \\
Mean length of stay (mean \pm SD) & $20 \pm 12$ \\
ICU & $10 \pm 9$ \\
Intermediate outcomes & \\
Late deaths & $0(0)$ \\
Reintervention & $1(6)$ \\
False lumen thrombosis & $14 / 16(88)$ \\
\hline
\end{tabular}

$S D$, Standard deviation; $I C U$, intensive care unit.

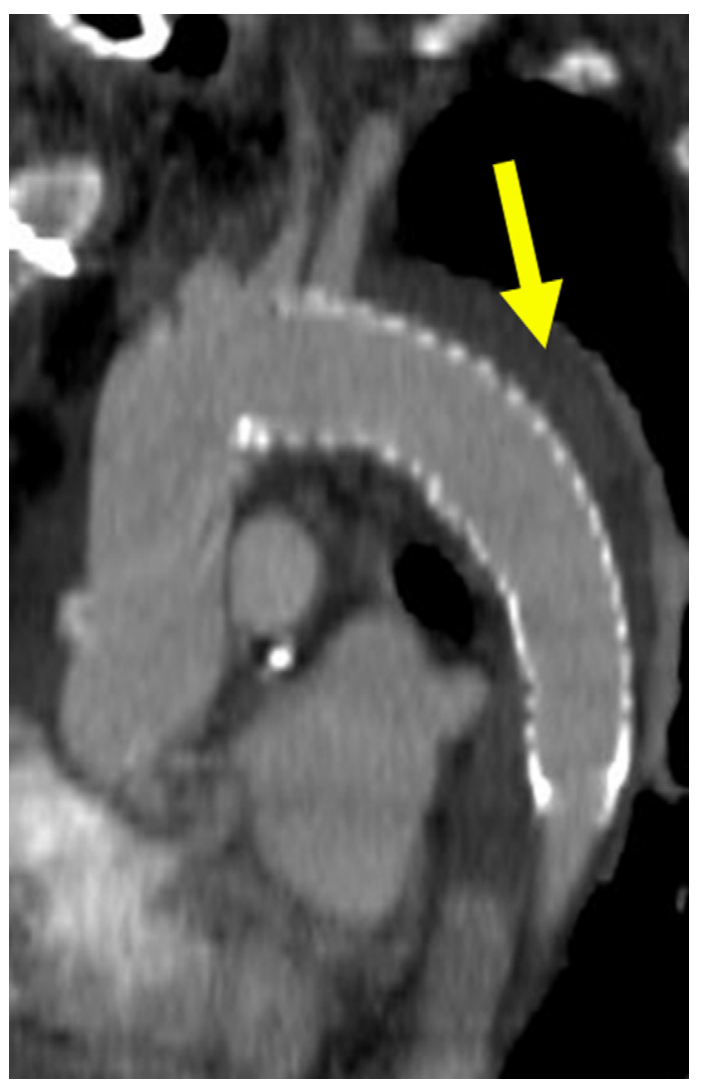

FIGURE 3. Maximum intensity projection 3-dimensional reconstruction of the postoperative arterial phase contrast-enhanced CT scan demonstrating thrombosis of the false lumen (arrow).

vulnerable to late complications is the isthmus portion (Figure 3 ). ${ }^{3}$ Both of these concerns are addressed by the operation described in this article, even though the experience is limited by a still small number of patients. The initial intent of designing this operation was to address the more proximal descending aorta, but an unintended benefit discovered during this early experience is how important the use of the hybrid operating room can be to patients presenting with ischemia and the predicted poor outcome.

\section{CONCLUSIONS}

A novel simplified hybrid technique for acute type I dissection allows for safe, effective extended aortic repair while promoting false lumen thrombosis and remodeling of the treated segment. Performance in a hybrid room allows for expedited definitive treatment in those with ischemia. Long-term outcomes warrant continued investigation.

\section{References}

1. Hiratzka LF, Bakris GL, Beckman JA, Bersin RM, Carr VF, Casey DE Jr, et al. 2010 ACCF/AHA/AATS/ACR/ASA/SCA/SCAI/SIR/STS/SVM Guidelines for the diagnosis and management of patients with thoracic aortic disease. J Am Coll Cardiol. 2010;55:e27-129.

2. Subramanian S, Roselli EE. Thoracic aortic dissection: long-term results of endovascular and open repair. Semin Vasc Surg. 2009;22:61-8. Review. 
3. Tsai TT, Trimarchi S, Nienaber CA. Acute aortic dissection: perspectives from the International Registry of Acute Aortic Dissection (IRAD). Eur J Vasc Endovasc Surg. 2009;37:149-59.

4. Fattouch K, Sampognaro R, Navarra E, Caruso M, Pisano C, Coppola G, et al. Long-term results after repair of type a acute aortic dissection according to false lumen patency. Ann Thorac Surg. 2009;88:1244-50.

5. Svensson LG, Kouchoukos NT, Miller DC, Bavaria JE, Coselli JS, Curi MA, et al. Expert consensus document on the treatment of descending thoracic aortic disease using endovascular stent-grafts. Ann Thorac Surg. 2008;85(1 Suppl):S1-41.

6. Roselli EE, Soltesz EG, Mastracci T, Svensson LG, Lytle BW. Antegrade delivery of stent grafts to treat complex thoracic aortic disease. Ann Thorac Surg. 2010;90:539-46.

7. Ishihara H, Uchida N, Yamasaki C, Sakashita M, Kanou M. Extensive primary repair of the thoracic aorta in Stanford type A acute aortic dissection by means of a synthetic vascular graft with a self-expandable stent. $J$ Thorac Cardiovasc Surg. 2002;123:1035-40.

8. Uchida N, Ishihara H, Shibamura H, Kyo Y, Ozawa M. Midterm results of extensive primary repair of the thoracic aorta by means of total arch replacement with open stent graft placement for an acute type a aortic dissection. J Thorac Cardiovasc Surg. 2006;131:862-7.

9. Jakob H, Tsagakis K, Tossios P, Massoudy P, Thielmann M, Buck T, et al. Combining classic surgery with descending stent grafting for acute DeBakey type I dissection. Ann Thorac Surg. 2008;86:95-101.

10. Li-Zhong Sun, Qi Rui-Dong, Chang Qian, Zhu JM, Liu YM, Yu CT, et al. Surgery for acute type A dissection using total arch replacement combined with stented elephant trunk implantation: experience with 107 patients. J Thorac Cardiovasc Surg. 2009; 138:1358-62.

11. Tsagakis K, Pacini D, Di Bartolomeo R, Benedik J, Cerny S, Gorlitzer M, et al. Arch replacement and downstream stent grafting in complex aortic dissection: first results of an international registry. Eur J Cardiothorac Surg. 2011;39:87-94.

12. Di Bartolomeo R, Di Marco L, Armaro A, Marsilli D, Leone A, Pilato E, Pacini D. Treatment of complex disease of the thoracic aorta: the frozen elephant trunk technique with the e-vita open prosthesis. Eur J Cardiothorac Surg. 2009; 35:671-5.
13. Pochettino A, Brinkman WT, Moeller P, Szeto WY, Moser W, Cornelius K, et al Antegrade thoracic stent grafting during repair of acute DeBakey I dissection prevents development of thoracoabdominal aortic aneurysms. Ann Thorac Surg. 2009;88:482-9.

14. Lima B, Roselli EE, Soltesz EG, Johnston DR, Pujara AC, Idrees J, Svensson LG Modified and "reverse" frozen elephant trunk repairs for extensive disease and complications after stent grafting. Ann Thorac Surg. 2012;93:103-9.

15. Ando M, Takamoto S, Okita Y, Morota T, Matsukawa R, Kitamura S. Elephant trunk procedure for surgical treatment of aortic dissection. Ann Thorac Surg. 1998;66:82-7.

16. Ius F, Hagl C, Haverich A, Pichlmaier M. Elephant trunk procedure 27 years after Borst: what remains and what is new? Eur J Cardiothorac Surg. 2011; 40:1-11.

17. Trimarchi S, Nienaber CA, Rampoldi V, Myrmel T, Suzuki T, Mehta RH, et al Contemporary results of surgery in acute type A aortic dissection: The International Registry of Acute Aortic Dissection experience. J Thorac Cardiovasc Surg. 2005;129:112-22.

18. Flores J, Kunihara T, Shiiya N, Yoshimoto K, Matsuzaki K, Yasuda K. Extensive deployment of the stented elephant trunk is associated with an increased risk of spinal cord injury. J Thorac Cardiovasc Surg. 2006;131:336-42.

19. Greenberg RK, Lu Q, Roselli EE, Svensson LG, Moon MC, Hernandez AV, et al Contemporary analysis of descending thoracic and thoracoabdominal aneurysm repair: a comparison of endovascular and open techniques. Circulation. 2008; 118:808-17.

20. Schepens MA. Editorial comment: will the elephant trunk become frozen? Eur J Cardiothorac Surg. 2011;40:11-2.

21. Pujara AC, Roselli EE, Hernandez AV, Vargas Abello LM, Burke JM Svensson LG, Greenberg RK. Open repair of chronic distal aortic dissection in the endovascular era: implications for disease management. J Thorac Cardiovasc Surg. 2012;144:866-73.

22. Kang WC, Greenberg RK, Mastracci TM, Eagleton MJ, Hernandez AV Pujara AC, Roselli EE. Endovascular repair of complicated chronic distal aortic dissections: intermediate outcomes and complications. J Thorac Cardiovasc Surg. 2011;142:1074-83. 